\title{
QUALITY MANAGEMENT IN THE NEW PRODUCT DEVELOPMENT: A PPAP APPROACH
}

\author{
DOI: 10.12776/QIP.V17I2.150
}

\author{
JOHANNA EMILIA HERMANS, YANG LIU
}

\section{INTRODUCTION}

Modern companies have been focused on producing own final products and have been decided to buy all components from suppliers. There are often many different supplier firms, from big, well-known listed companies to small family firms with a couple of employees. To ensure the high quality of the final product the buyer companies have to be sure that all components are following the quality requirements and expectations. The purpose of this paper is to test and analyze Production Part Approval Process (PPAP) as a tool to build quality into the new product and processes and ensure that the product meets the customer expectations. The purpose is to test the usability of PPAP to ensure that the supplier has understood what is expected from component, reduce quality defects in production lines by preventing them and doing things right at the first time.

This article includes four parts. The first part is introducing part including the description of the study, targets and backgrounds and research question. The second part includes a theoretical framework of PPAP, quality management and new product development processes in the form of literature review. The third part includes an empirical part of this study in whicha case study related to PPAP and its effects to new product development (NPD) is described. In the case study we have tested PPAP with three suppliers from three different kinds of component fields, and the results are summazied and discussed.

Research questions:

- Is PPAP suitable tool to build quality into the product and process in the beginning of the NPD process?

Research method is qualitative method using so called case-study to research the suitability of PPAP as a tool for quality management. Supplier's resources and competences were also quite different and that is why these firms were chosen as pilot firms. 
Qualitative method is a holistic way of information gathering and material has collected in a real life situation. The qualitative research method studies the why and how of decision making, not just what, where and when. Qualitative method as a research method favors often people as an instrument of the gathering. Qualitative method is a method to deeply explore, understand and interpret phenomena within its natural setting. By using a qualitative methodology, the researcher wants to collect richer and more comprehensive data and get a more detailed picture of issue or case. Qualitative research trusts in own observations and the starting point is to describe a real life situation. That is why the smaller sample sizes are much more appropriate than larger. (Hirsijärvi, et al., 2010, pp. 150-151).

\section{LITERATURE REVIEW}

\subsection{Quality management}

Earlier, quality has been understood as a defect free product. Since then, quality has become an organization's comprehensive business concept and a critical success factor. It is linked to all operations in the company. Defining quality has become more and more difficult because of the development of quality thinking and growing importance of quality. Quality concept largely depends on the situation which varies case by case (Lecklin, 2002, pp. 17-325).

What is quality exactly? There must be as many definitions as it is people who have written about it. We favor the following IBM's definition of quality (Van Weele, 2005, p. 192):

"Quality is the degree in which customer requirements are met. We speak of a quality product or quality service when both supplier and customer agree on requirements and these requirements are met".

Crosby (1988, p. 7) says that "Quality is free". According to Crosby, quality is the fulfillment of the specified requirements which can be measured. Crosby advises to study tasks as processes, find the areas that need improving and build quality in processes. Crosby highlights actively prevent problems to get quality right at the first time instead of wasting time to inspect final product and repair defects (Hannukainen, 1993, pp. 21-23).

According to Deming, quality is all those aspects and characteristics that product or service meets the needs and expectations. He highlights that when decreasing the variance of the process, the consequence is the better quality and productivity (Hannukainen 1993:19-21).

Juran highlights three points in his trilogy, an approach to cross-functional management: quality planning, quality control and quality improvement (Hannukainen, 1993, p. 24). Hannukainen (1993, p. 11) divides quality in four parts: 
- Product oriented

- Function oriented

- Customer oriented

- Value oriented

Product oriented quality is the sum of the properties of the product. Product oriented quality can be defined by metrics. According to this definition, better quality requires higher costs, because some new property increases costs.

Function oriented quality is defined as a uniformity or equivalence to product specification. It is effective and faultless of the function. Function oriented quality is strongly linked to preventive problem solving and cost reduction.

Customer oriented quality fulfills customers' needs and expectations and highlights suitability for use. Products with high quality fulfill customers' expectations, but high quality can be defined many different ways and different kinds of peoples recognize it many different ways. According to Ulrich and Eppinger (2000), success of manufacturing companies depends mostly on their ability to identify the customer needs and create products that meet their needs and are produced at low cost.

\subsection{New product development process}

New product development can be used to solve all above mentioned kinds of problems. According to Ulrich and Eppinger (2000), to succeed as a company and get as high customer satisfaction as possible it is very important to be familiar with the characteristics of successful product development. They also say that the performance of a new product development can be evaluated by looking at product quality, product cost, time, cost and capability of development

The new product development is a process which is designed to develop, test and ensure the profitability of the new products. Therefore, the managers reduce and control the uncertainty activities before the next phase is implemented according to the integrity of information. It can ensure the improvement of the performance and quality of NPD (Kuan, et al., 2010).

Ulrich and Eppinger have developed the process including six different phases shown in Figure 1. (Viitaniemi, et al. 2010). 


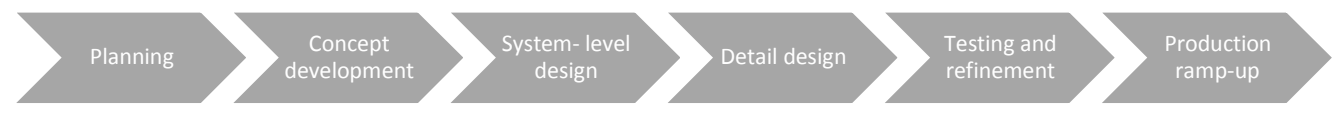

Figure 1 - Product development process (Viitaniemi et al. 2010)

The planning phase is a link for research and technology development activities. The planning phase begins with corporate strategy including the assessment of technology development and market objectives. The output of this phase is a project mission statement, which specifies the market for the product, business goals, constraints and key assumptions.

In the concept development phase it is time to identify the target market, generate and evaluate alternative product concepts, select one or more concepts for further development and testing. The system-level design phase requires the definition of the product architecture and major sub-systems and interfaces. Refining industrial design, identifying suppliers for key components and developing a plan for product options and an extended product family helps the development team to create a clear picture of a future product. These activities allow the process to move further into the phase of detail design which includes the complete specification of the geometry, tolerances and materials to all parts in the product (Viitaniemi, et al., 2010).

The end of the product development process is the product ramp-up making the product available for purchase. Before ramping up a new product, it has to be tested and refined. When ramping up a new product or new manufacturing location it is needed to ensure that the product and process is well-planned and organized before starting production. The ramp up phase includes a preparation stage, a verification stage and a production start phase.

This phase involves the construction and evaluation of prototypes of the product. The development team tests the reliability, performance and lifetime of the product. In the last phase, evaluation of early production output can be done and after that it is possible to begin the operation of the entire production system. This phase is critical as its purpose is to train the workers and identify problems in the production process. It is easier to ensure the quality of the product and divide all the work into different parts in the clearly divided process. Using phases in the product development process gives the opportunity to develop and also evaluate all activities included in the process (Viitaniemi, et al., 2010).

It is very difficult to develop products that become favorites on the market. According Ulrich and Eppinger (2000) the new product development is an operation that includes lots of uncertainties. Almost $50 \%$ of the new product 
development costs arise due to its failure. The main goal is to identify the customer needs and to respond to them quickly and profitably.

\subsection{Production part approval process (PPAP)}

It is important to ensure that the company's processes are providing the quality that customers expect (Krajewski, et al., 2010, p. 228). Process control is a demand of successful quality work. Because of process way of thinking, operations of organizations can be better understood and all connected matters and dependencies can be seen. The actual process data are needed from the present state, if product quality and manufacturing process improvement is wanted (Salomäki, 1999, pp. 145-155).

Chrysler, Ford and General Motors (AIAG, 2006) have developed a special process that defines generic requirements for production part approval, including bulk materials and production processes. The purpose of Production Part Approval Process (PPAP) is to determine that all customer engineering design record and specification requirements are properly understood by the organization. It also determines that the manufacturing process has the potential to produce product consistently meeting the requirements during actual production run at the quoted production rate. PPAP is applied to organizations supplying production parts, production materials, service parts, or bulk materials to the automotive industry (AIAG, 2006). The main components of PPAP are:

1) Design Records

A copies of the drawings. This can be a copy of the customer drawing if the customer is design responsible. In that case it will be sent together with the Purchase Order (PO). If supplier is design responsible this is a released drawing on the supplier's release system.

2) Authorized Engineering Change Documents

This is a document that shows the detailed description of the change.

3) Engineering Approval

This approval is the Engineering trial with production parts performed at the customer plant. A "temporary deviation" is required to send parts to customer before PPAP.

4) Design Failure Mode and Effect Analysis (DFMEA)

A copy of the DFMEA, reviewed and signed-off by supplier and customer. If a customer is design responsible, usually customer may not share this document with the supplier. This is a list of all critical or high impact product characteristics and should be shared with the supplier, so they can be addressed on the PFMEA and Control Plan.

5) Process Flow Diagram

This is a copy of the Process Flow, indicating all steps and sequence in the manufacturing process, including incoming components. 
6) Process Failure Mode and Effect Analysis (PFMEA)

The PFMEA follows the Process Flow steps, and indicate "what could go wrong" during the manufacturing and assembly of each component. It can be used to assess the potential risks and to prioritize the risk level. Whit a help of FMEA the corrective actions can be focused to right topics and areas. FMEA approaches the risk analysis from the viewpoints of severity, occurrence and detection probability. Each of these factors are scored and their outcome is a Risk Priority Number (RPN).

7) Control Plan - The Control Plan follows the PFMEA steps, and provides more details on how the "potential issues" are checked in the incoming quality, assembly process or during inspections of finished products. Control plan is used and maintained throughout the product life cycle. Early in the product life cycle its primary purpose is to communicate and document the initial plan for process control. Later, it guides manufacturing in how to control the process and ensure product quality. Eventually, the $\mathrm{CP}$ remains as a living document, reflecting the current methods of control, and measurement system used. The CP is updated as measurement systems and control methods are improved and evaluated.

8) Measurement System Analysis Studies (MSA)

MSA usually contains the Gage R\&R for the critical or high impact characteristics. It contains also a confirmation that gauges used to measure these characteristics are calibrated. Measurement system analysis (MSA) is specified for monitoring and measuring devices and methods. It is used to check the identified characteristics against the specification.

Measurement data, or some statistic calculated from them, is compared with statistical control limits of the process. If the comparison indicates that the process is out of statistical control, then an adjustment of some kind is made. Otherwise, the process is allowed to run without adjustment.

9) Dimensional Results

A list of every dimension noted on the ballooned drawing. This list shows the product characteristics, specifications, the measurement results and the assessment showing if this dimension is "ok" or "not ok". Usually a minimum of 6 pieces is reported per product/process combination.

10) Records of Material / Performance Tests

A summary of every test performed on the part. This summary is usually in a form of the Design Verification Plan and Report, which lists every individual test, when it was performed, the specification, results and the assessment ok/nook. If there is an Engineering Specification, usually it notes on the print.

In addition, this section lists all material certifications (steel, plastics, plating, etc.), as specified on the print. The material certification shall show compliance with the specific call on the print. 
11) Initial Process Studies

This section shows all Statistical Process Control (SPC) charts affecting the most critical characteristics. The intent is to demonstrate that critical processes have stable variability and that is running near the intended nominal value.

12) Qualified Laboratory Documentation

A copy of all laboratory certifications of the laboratories that performed the tests reported in section 10 .

13) Appearance Approval Report

Applicable for components affecting appearance only.

14) Sample Production Parts

A sample from the same lot of initial production run. The PPAP package usually shows a picture of the sample and where it is kept.

15) Master Sample

A sample signed off by customer and supplier, that usually is used to train operators on subjective inspections such as visual or for noise.

16) Checking Aids

When there are special tools for checking parts, this section shows a picture of the tool and calibration records, including dimensional report of the tool.

17) Customer-Specific Requirements

Each customer may have specific requirements to be included on the PPAP package.

18) Part Submission Warrant (PSW)

This is the form that summarizes the whole PPAP package. This form shows the reason for submission (design change, annual revalidation, etc.) and the level of documents submitted to the customer. There is a section that asks for "results meeting all drawing and specification requirements: yes/no" refers to the whole package. If there are any deviations the supplier should note on the warrant or inform that PPAP cannot be submitted (AIAG, 2006).

\section{RESEARCH METHODOLOGY}

PPAP defines generic requirements for production part approval, including production and bulk materials. PPAP model used in the case company bases on the AIAG's (Automotive Industry Action Group) principles, as shown in Figure 2. The purpose of PPAP is to determine if all customer engineering design record and specification requirements are properly understood by the organization, and that the manufacturing process has the potential to produce products meeting these requirements consistently - during an actual production run at the quoted 
production rate. The PPAP ensures also that the process produces sufficient quality. The content of the PPAP is defined during the component's proto state. The target is that the product requirements are understood and the process is effective enough.

PPAP will be started when there exists a prototype of the product. Product development responsible and quality engineer will define the level of the PPAP and what kinds of documents are required. It is depending on supplier what kind of elements are required. There may be a big listed company which processes and quality assurance is on a good level and only a few stages of PPAP are necessary. There can also be a small family company and in that case a heavy and broad PPAP is impossible to carry through because of lack of resources. When PPAP is carried through the product is ready for mass production. The purpose of PPAP is to continuously develop quality level, actions and processes and to ensure the capability of new products and processes.

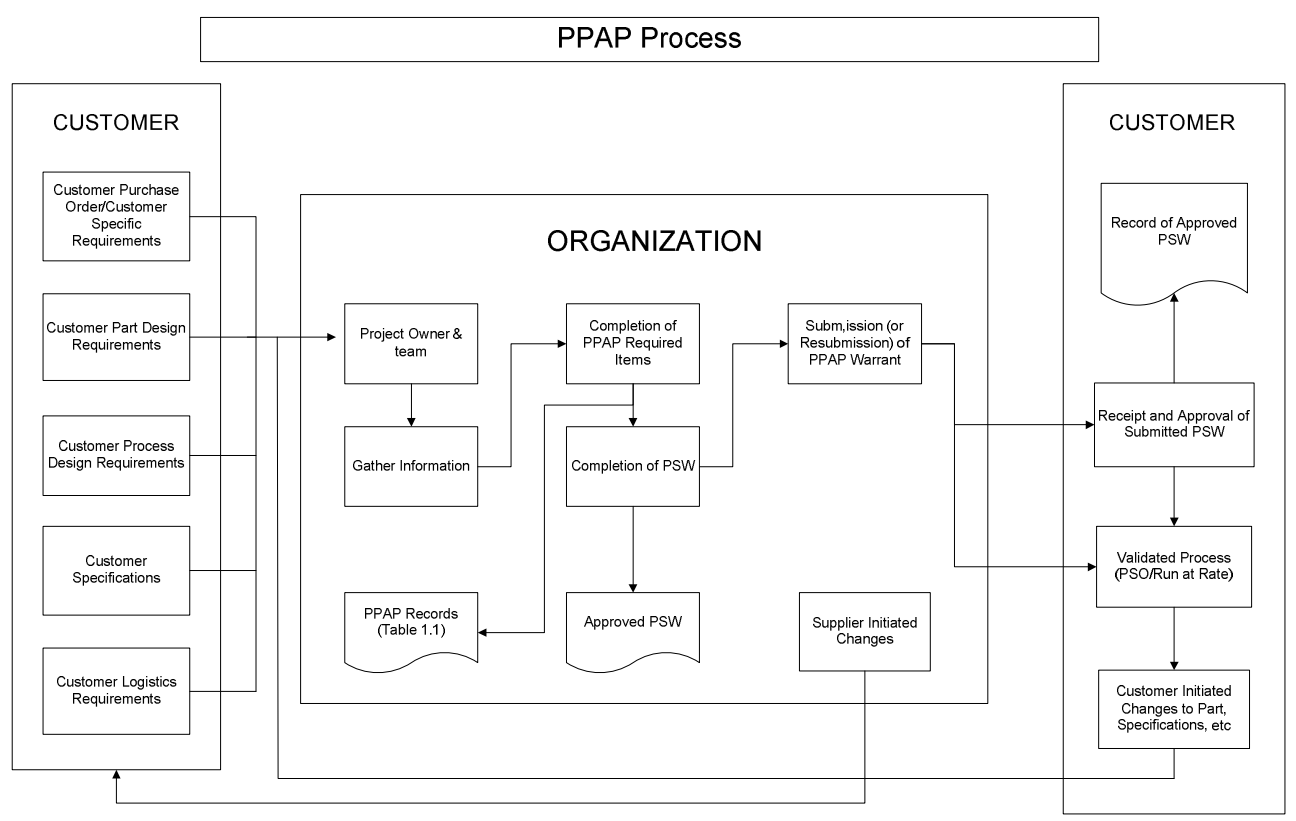

Figure 2 - PPAP (AIAG, 2006)

\subsection{Research sample and data collection}

Case studies started with the pilot phase where the target was to test and refine the PPAP model. The target was to test the suitability of using this model to build the quality into the product and processes. PPAP requirements were defined, documents and information were gathered through interviews, meetings and required communication through the whole pilot - project. There were also trainings organized by customer and suppliers were also invited to learn more about PPAP. There were involved in the quality engineers, quality managers, key 
account managers, purchasers, the R\&D Manager, NPD managers and engineers. PPAP model was tested with suppliers in practice and refined so it would be useful with all suppliers in product development process. Suppliers produced all needed documents and gave feedback which are sampled for analyzing. During the pilot phase there were changes especially in material declaration part in PPAP. There were noticed that the changes in suppliers' processes are visible after a few years and need to be audited later according to the auditing system.

Table 1 - PPAP definitions

\begin{tabular}{l|l|l} 
Company & Field & Documents \\
\hline Supplier 1 & Power electronic & $\begin{array}{l}\text { Process flow, PFMEA, Control plan, Dimensional } \\
\text { Measurement Report, Records of Material/Performance } \\
\text { Tests, Capability Test, Appearance approval report, } \\
\text { Sample production parts, Master sample, PSW }\end{array}$ \\
\hline Supplier 2 & Mechanics & $\begin{array}{l}\text { Process flow, PFMEA, Control plan, Dimensional } \\
\text { measurement report, Records of material/Performance } \\
\text { Test, Capability test, Appearance approval report, Sample } \\
\text { production parts, Master sample, PSW }\end{array}$ \\
\hline Supplier 3 & Plastic molding & $\begin{array}{l}\text { Process flow, PFMEA, Control plan, Dimensional } \\
\text { measurement report, Records of material/Performance } \\
\text { Test, Capability test, Appearance approval report, Sample } \\
\text { production parts, Master sample, PSW }\end{array}$
\end{tabular}

\subsection{Data analysis}

The data analysis was based on the documents, comments and e-mails collected during the case study. We also had meetings together with the pilot suppliers to reflect results and opinions. This was useful to familiarize with the data and to fill the gaps in the documents. A brief summary from each supplier was prepared, so that a meaningful data could be documented. Also steering group had a couple of meetings to discuss whole project and analyze data. Documents and comments were compared against each other's and analyzed the level of preparing documents and information. The supplier's comments are presented in Table 2. 
Table 2 - Supplier's feedback about PPAP

\begin{tabular}{|c|c|}
\hline Company & Supplier comments \\
\hline Supplier 1 & $\begin{array}{l}\text { - The extent of the work is challenging } \\
\text { - Maybe the extent should be smaller } \\
\text { - Records of material affect lots of extra costs because it needs to be } \\
\text { - done by chemistry } \\
\text { - } \text { Documentations need to be on a better level } \\
\text { - Positive attitude to get this work } \\
\text { - Corrective actions }\end{array}$ \\
\hline Supplier 2 & $\begin{array}{l}\text { - Starting requires that all documents are sent together with the orders } \\
\text { and new products. } \\
\text { - Critical dimensions must be marked to the documents and possible } \\
\text { ratings for them. } \\
\text { - Without any documents and drawings PPAP cannot be started } \\
\text { - PPAP needs to be carried through a couple of times to get it flexible } \\
\text { and routine work } \\
\text { - After that it is possible to see how much resources PPAP needs, how } \\
\text { - } \text { much time it takes and what are the effects of the pricing } \\
\text { - impossible to get all information } \\
\text { - A great possibility to get documentation and communication to the } \\
\text { - Notter level } \\
\text { - } \text { Validation and verification } \\
\text { - Control special or critical characteristics }\end{array}$ \\
\hline Supplier 3 & 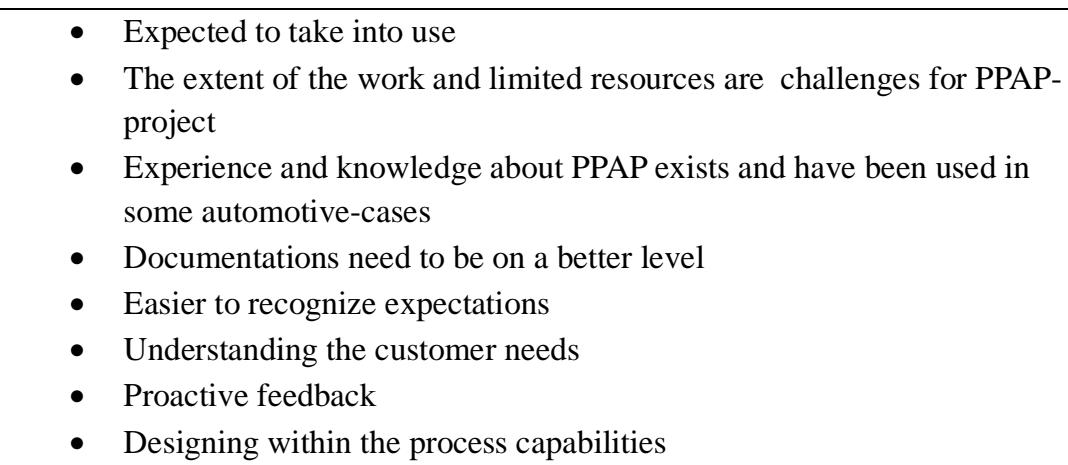 \\
\hline
\end{tabular}




\section{RESULTS}

The purpose of this paper was to test and analyze Production Part Approval Process as a tool to build quality into the new product and processes and ensure that it meets the customer expectations. The purpose was to find out if PPAP is capable tool to ensure that the supplier has understood what is expected from component, reduce quality defects in production lines by preventing them and doing things right at the first time. Turning to the research questions the target was to find out if PPAP is suitable tool to build quality into the product and process in the beginning of the NPD process?

To give direct answer to the research question we could say that: "Yes, it is suitable tool and have many positive side effects too from better documentation and communication to cooperation with suppliers. It is suitable tool because it helps to take into account the entirety of the NPD process. There is many different important things that should be taken into account, when developing a new product, for example manufacturability, work instructions, tools, which have some effect to the quality of the final product. It is very suitable tool to take into account the problems and risks, what can go wrong in the desing phase and production phase. Into the design FMEA is listed all things that can go wrong when desinging the product, and these are controlled in process FMEA and control card. It is also very clear tool and easy to use. This helps to include a quality management into the process from the beginning of the process. There are also many things that need to be updated or corrected before PPAP can be used.

One of the most important highlighted findings for usage of this kind of tool is the importance of communication and documentation. Every supplier mentioned these points under meetings (See table 2.). Because of poor or lack of communication and documentation the problems can be bigger than they were at the beginning and there can occur a lot of misunderstandings when documentations are poor or it does not exist. PPAP ensures that the documentation is on needed level and both parties ( supplier and customer ) understood what is expected and what can be expected. PPAP helps to make product development an independent process which develops itself and absorbs all the new aspects and perspectives of the changing world, society and environment. It is important that the implementation of this tool would benefit all parties, not only customer. Feedback has been positive and this study is striving to increase the know-how and understanding of the benefit and usage of these kinds of tools and methodsA practical benefits are a better quality from the beging of the product development process to the customer, with the help of the better documentation, better communication, documented risks, improved processes at the supplier which gives a result $\mathrm{s}$ like a better quality of components.

New product development engineers and managers found that PPAP enabled them to better understand the customers. In turn, PPAP enabled the new product development department to demonstrate commitment and support to their 
suppliers. Communicativebenefits were also experienced in everyday working. On the other side, communication was felt to be hampered by the often confusing and complex systems and abstract language. During this pilot project a stakeholder begun more and more to speak "same language". In terms of the suitability of PPAP as a tool being experienced, it was largely of resources, involving the skills and knowledge and also lack of customers' documents which get most feedback and caused problems and extra work.

The overload was experienced when testing PPAP and producing documents. In the beginning were noticed some kind of "us and them" feeling across customer and supplier when sitting around the meeting board. Although it allowed customers and suppliers to better become aware of one another's process, routines, quality assurance routines, new product development and everyday working. There were noticed the very lack of process discipline, documentation and commonly understood procedural frameworks as a cause of re-work, project variation and a failure to make effective work (See Table 2.).

According to supplier feedback this is a great possibility to get documentation and communication to the better level because drawings and documents including critical characteristics and dimensions have been insufficient at the customer site. PPAP projects were seen as a great communication channel and the channel to better understand each other's. Concerns aroused the extent of work, lack of documentation and poor drawings as well as the lack of PPAP experience and know-how. Limited resources to get through this kind of process at supplier site were seen challenging. The contribution is findings from meetings (See the Table 2.) which shows that the AIAG's PPAP model can improve supplier processes, and communication between supplier and customer. These are the key factors in quality management.

\section{DISCUSSION AND CONCLUSIONS}

The process of successful NPD requires much skill and disciplines. There are lots of different reasons why NPD is so challenging for an NPD team. New product development and innovations are one of the most profitable ways for a company to get a stronger place at the market, create better possibilities for further product development, growth, compete in markets and find new market areas and make an impact to the customers. There are many factors that make product development challenging and more complicated. A changing environment, changing customers' preferences, multiple choices, time pressure, new competitors in the market, changes in standards and technical requirements and the world's financial situation - just to name a few (Ulrich and Eppinger , 2000).

Following the process models requires reorganization of the strategy, reconsideration of goals and priorities, systematic way of doing things, changing the attitude towards product development and process way of thinking and also understanding the importance of quality management. In order to create a 
winning product the company has to create something new which differs from the competitive products and brings special and unique benefits to the users. Finding new ideas and solutions has its effects to the quality level and that extends also to the suppliers' processes. New product development and quality management go hand in hand representing a commitment to better order. Product development is born from innovation creating new products and services. New product or service generates instability of the process and variation of the quality during ramp up- and learning phase.

Quality activities in production ensure the faultlessness of the products or services and the expected functions of the processes. Quality management has changed from the characteristic of the product or service to one of the biggest success factors of the organization. It is important to build the quality into the processes and product and create meters metrics to measure it. In addition to its theoretical contribution to new product development and quality management literature, this paper offers several implications for those responsible for managing quality in new product development processes.

PFMEA, Control plan and MSA are the most important steps in the PPAP. A Process Failure Mode and Effects Analysis (PFMEA) follow the process flow steps and indicate possible implications during the manufacture and assembly of each component. The control plan provides more details on how the "potential issues" are checked during the whole manufacturing process. The measurement system analysis study (MSA) is a specially designed experiment and its purpose is to identify the variation of the components in the measurement. The common tools and techniques of MSA are usually selected and determined by the characteristics of the measurement system itself. Production can be started and ramped up to the required production level after an approved verification. When starting production, it must be ensured, that all documents (such as working instructions) are up-to-date, all personnel have the required training and all the needed capacity is available (human and machine capacity).

The deployment of the PPAP in case company requires the checking of new product development processes. The most important things are to follow decided process steps and include suppliers in the process if possible. Also documentations and drawing needs to be on better level and include critical metrics and parameters. New product development would be more effective and PPAP possible to get through. This supports the elimination of defects in the beginning of the new product development process. Product development departments work often separately from others and there are many peoples in other departments who don't know what the new product designers are doing.

What was valued about this study was the manner in which the stakeholders could use to facilitate a sense of partnerships or co-workers aiming the same goals rather than have a traditional customer-seller relationship. While this study offers new insights into the quality management of new product development processes there are a number of limitations. The study only covers three medium 
sized companies making generalization a little bit difficult. Future studies may wish to consider other tools for developing quality in new product development processes and compare those to PPAP as a tool.

\section{REFERENCES}

AIAG Automotive Industry Action Group, 2006. Production Part Approval Process. Chrysler Corporation, Ford Motor Company, General Motor Corporation, Southfield.

Crosby, Philip B., 1988. Kvalitet är gratis: Hur man säkerställer kvalitet. Utbildningshuset Studentlitteratur. 277 p., ISBN 91-44-99301-3.

Hannukainen, Timo, 1993. Laatuyritykset - Laatujohtaminen maailman valioyrityksissä. Tammerpaino Oy. 316 p., ISBN 951-817-570-5.

Hirsijärvi, Sirkka, Remes, Pirkko and Sajavaara, Paula, 2010. Tutki ja kirjoita. Tammi. 464 p., ISBN 978-951-314-8362.

Krajewski, Lee, Larry Ritzman \& Manoj Malthora 2010. Operations Management. Processes and Value Chain. Prentice Hall, New Jersey. 672 p., ISBN 978-0-13-245891-7.

Kuan, Meng-Jong, Tzeng, Gwo-Hshiung \& Hsiang Chia-Chun, 2010. Exploring the Innovative Quality System Structure Model for NPD Process by combining DANP with MCDM Model. International Journal of Innovative Computing, Information and Control.

Lecklin, Olli ,2002. Laatu yrityksen menestystekijänä. Gummerus Kirjapaino Oy, Jyväskylä. 464 p., ISBN 952-14-0519-8.

Salomäki, Rauno, 1999. Hyödynnä SPC - Suorituskykyiset prosessit. Metalliteollisuuden Kustannus Oy. 398 p. ISBN 951-817-707-4.

Ulrich, Karl., Eppinger, Steven, 2000. Product design and development. 2. Ed. Boston: Irwin McGraw-Hill. ISBN 0-07-229647-X.

Van Weele, Arjan J., 2005. Purchasing \& Supply Chain Management: Analysis, Strategy, Planning and Practice. Thomson Learning 2005. 364 p., ISBN 1-84480-024-7.

Viitaniemi, Juhani., Aromaa, Susanna., Leino, Simo-Pekka., Kiviranta, Sauli., Helin, Kaj., 2010. Integration of User-Centered Design and Product Development Process within a Virtual Environment. Practical case KVALIVE. Finland: VTT. Available from Internet: <URL: http: //www.vtt.fi/publications/index.jsp> ISSN 1459-7683. 


\section{ABOUT THE AUTHORS}

Johanna Hermans, Main author, Master student of Industrial engineering, Faculty of Technology, Department of Production, University of Vaasa, PL 700, 65101 Vaasa, Finland, e-mail: johanna.hermans9@gmail.com.

Yang Liu, Corresponding author, advisor, D.Sc. (Tech.), University Lecturer, Faculty of Technology, Department of Production, University of Vaasa, PL 700, 65101 Vaasa, Finland, e-mail: yli@uva.fi. 